University of Wollongong

Research Online

Faculty of Business - Papers (Archive)

Faculty of Business and Law

$1-1-2014$

Dynamic forecasts of financial distress of Australian firms

Maria Kim

University of Wollongong, mhykim@uow.edu.au

Graham Partington

University of Sydney

Follow this and additional works at: https://ro.uow.edu.au/buspapers

Part of the Business Commons

Research Online is the open access institutional repository for the University of Wollongong. For further information contact the UOW Library: research-pubs@uow.edu.au 


\title{
Dynamic forecasts of financial distress of Australian firms
}

\author{
Abstract \\ Dynamic forecasts of financial distress have received far less attention than static forecasts, particularly \\ in Australia. This study, therefore, investigates dynamic probability forecasts for Australian firms. Novel \\ features of the modelling are the use of time-varying variables in forecasts from a Cox model. Not only is \\ this one of relatively few studies to apply dynamic variables in forecasting financial distress, but to the \\ authors' knowledge it is the first to provide forecasts of survival probabilities using the Cox model with \\ time-varying variables. Forecast accuracy is evaluated using receiver operating characteristics curves and \\ the Brier Score. It was found that the dynamic model had superior predictive power, in out-of-sample \\ forecasts, to the traditional Cox model and to the logit model. \\ Keywords \\ firms, australian, dynamic, distress, financial, forecasts \\ Disciplines \\ Business \\ Publication Details \\ Kim, M. H. \& Partington, G. (2014). Dynamic forecasts of financial distress of Australian firms. Australian \\ Journal of Management, 40 (1), 135-160.
}




\section{Dynamic forecasts of financial distress of Australian firms}

Australian Journal of Management

\title{
Maria H. Kim
}

Faculty of Business, University of Wollongong, Australia

\section{Graham Partington}

Business School, The University of Sydney, Australia

\begin{abstract}
Dynamic forecasts of financial distress have received far less attention than static forecasts, particularly in Australia. This study, therefore, investigates dynamic probability forecasts for Australian firms. Novel features of the modelling are the use of time-varying variables in forecasts from a Cox model. Not only is this one of relatively few studies to apply dynamic variables in forecasting financial distress, but to the authors' knowledge it is the first to provide forecasts of survival probabilities using the Cox model with time-varying variables. Forecast accuracy is evaluated using receiver operating characteristics curves and the Brier Score. It was found that the dynamic model had superior predictive power, in out-of-sample forecasts, to the traditional Cox model and to the logit model.
\end{abstract}

\section{Keywords}

Baseline hazard, dynamic forecasts, financial distress prediction, proportional hazard, survival analysis, time-varying Cox regression model

\section{Introduction}

Research on bankruptcy prediction has been of substantial interest to accounting and finance academics and practitioners for the last four decades. Bankruptcy prediction models generally provide measures of financial distress and are routinely used by researchers to evaluate the financial health of companies (Grice and Dugan, 2001). However, it is noted that much of the previous work in

\section{Corresponding author:}

Maria H Kim, School of Accounting, Economics and Finance, Faculty of Business, University of Wollongong, Northfields Ave, Wollongong, NSW 2522, Australia.

Email: mhykim@uow.edu.au

Final transcript accepted 3 November 2013 by Kathy Walsh (AE Finance). 
financial distress prediction focuses on static predictions and uses static variables in estimating the predictive model.

In this study the goal is to make dynamic predictions and to use dynamic variables in estimating the model. With dynamic predictions the probability of financial distress is allowed to vary over the forecast period. With dynamic variables the model estimation allows for changes in the financial characteristics of a firm over time.

The motivation for this paper is threefold. Firstly, the dynamic forecasts of the probability vector for failure $f_{t}$ to $f_{t+n}$ (where $f_{t}$ is the probability of failure at time $t$ ) have been much less explored than the static forecast of a single failure probability $f$. Secondly, relatively little use has been made of dynamic forecasting variables. In most applications, including a data vector of, say, the last five years, profitability in forming a forecast requires five separate profitability variables in the model, and this is not commonly done. ${ }^{1}$ In the approach used in this study, the vector of data is represented by a single profitability variable. Thirdly, one of the most popular techniques for survival analysis is the Cox proportional hazards model (Cox, 1972). Unfortunately, for reasons discussed below, forming forecasts is problematic when a Cox proportional hazards model contains dynamic variables. In this study, a procedure is implemented to overcome this problem.

The work on estimating models that allows for time-varying probabilities of financial distress began in the mid-1980s (for example, Crapp and Stevenson, 1987). These models use the techniques of survival analysis and have attracted increasing attention following the dynamic model of Shumway (2001). Despite the growing use of survival analysis in modelling financial distress, relatively little attention has been given to the use of dynamic variables in estimating these models. Initially this was because of computational difficulties in estimating models with time-varying predictor variables, sometimes referred to as 'time-dependent covariates' (Allison, 1984: 36), and even when this problem was overcome, a problem remained in making forecasts when using the Cox model.

A key element in forecasts when using the Cox proportional hazards model is the baseline hazard. When making a forecast, the baseline hazard is scaled up, or down, according to the firm's risk factors, and this scaled hazard is used to compute the probability of financial distress. When timevarying variables are introduced into the Cox model, forming estimates of the baseline hazard has been problematic. Consequently, making forecasts has also been impracticable with time-varying variables in past financial distress studies.

The contribution of this paper is that a procedure is implemented to overcome these problems. The method used is based on a medical research paper by Chen et al. (2005), which applied the Cox model with time-varying variables to find the effect of biochemical covariates on deaths attributed to liver cancer. Following the approach of Chen et al., a Cox regression model with time-varying covariates is constructed for the prediction of financial distress in this study.

Using firm-specific data on Australian Securities Exchange (ASX) listed firms from 1995 to 2006, a time-varying Cox hazards model is developed with nine predictor variables measuring profitability, leverage (book and market), liquidity, cash flow, growth opportunities (market-tobook ratio), size, past excess return and return volatility. Each variable makes use of all available yearly data, for firms that are in the estimation sample, for the full eight years (from 1995 to 2002). Liquidity, leverage (book and market), cash flow generating ability, market-to-book ratio and past excess return are found to be significant predictors of financial distress. Receiver operating characteristic (ROC) curves and the Brier Score show that the dynamic Cox model has some predictive power, showing better out-of-sample forecasts than both a standard Cox model and a static logit model.

The remainder of this paper is set out as follows. Section 2 reviews relevant literature in the area of corporate bankruptcy prediction. It also introduces survival analysis. Section 3 presents the 
methods to construct a Cox hazards model with time-varying variables and discusses Chen et al. (2005). After describing the data and explaining how predictive accuracy is evaluated in Section 4, Section 5 presents the results of parameter estimates and is followed by an assessment of the predictive accuracy of the model. Finally, Section 6 concludes and offers some possible directions for future research.

\section{Advances in bankruptcy prediction models}

A number of empirical approaches have been employed in bankruptcy prediction modelling since the pioneering work of Beaver (1966), Altman (1968) and Ohlson (1980). The traditional approach to predicting corporate bankruptcy has been to apply a statistical classification technique to a set of samples containing both bankrupt and non-bankrupt firms. The two most widely used techniques are multivariate discriminant analysis (Altman, 1968) and logit analysis (Ohlson, 1980). Predicting the bankruptcy of a firm requires classification where, given a set of classes (here, bankrupt and non-bankrupt) and a set of input data vectors (financial ratios), the task involved is to assign each input data vector to one of these classes.

Since the 1980s, the literature has progressed to non-parametric approaches such as recursive partitioning algorithms (Frydman et al., 1985), neural networks techniques (Coats and Fant, 1992; Odom and Sharda, 1990; Tam and Kiang, 1992; Wilson and Sharda, 1994) and survival analysis (Bandopadhyaya, 1994; Chen and Lee, 1993; Crapp and Stevenson, 1987; Kim et al., 1995; Lane et al., 1986; Wheelock and Wilson, 1995).

\section{I. Introduction to survival analysis}

Survival analysis is a statistical method specifically designed for the study of events, where observational units run through their lifetime, and the duration of time, until the event of interest occurs, is observed. An event can be defined as some qualitative change that occurs at a specific point in time that exhibits 'a relatively sharp disjunction between what precedes and what follows' (Allison, 1984: 9). Once the event of interest is defined, the probability of the event occurring is measured based on potential predictor variables.

One key feature of survival analysis is that it controls for both the occurrence and the timing of events. ${ }^{2}$ While other statistical models analyse an event's probability using variables based on data at one time point (e.g. logistic regression), survival analysis accommodate changes in the probability of the event due to changes in the values of variables over time (Routledge and Morrison, 2012). That is, it provides the probability that financial distress will occur at a time $T$ that lies beyond the time horizon $t$, for a range of values of $t$. Thus, a time dimension is embedded into both the dependent and independent variables of the model.

Therefore, survival analysis is a natural choice for bankruptcy prediction since it allows the estimation of the probability that a firm survives or goes bankrupt at each point in time $t$ over the forecast period, given the 'random nature of the lifetime' of a company (Peat, 2007: 303). From 2000 onwards there has been growing use of survival analysis in financial distress modelling (Bonfim, 2009; Campbell et al., 2008; Chava and Jarrow, 2004; Cole and Wu, 2009; Nam et al., 2008; Partington et al., 2001; Peat, 2007; Shumway, 2001; Wong et al., 2007).

While there are several recent Australian studies examining the risk of financial distress, most of them have focused on the use of the logit model (Gharghori et al., 2006; Hensher and Jones, 2007; Jones and Hensher, 2004), the probit model (Gray et al., 2006) and the Merton's optionbased model (Allen and Powell, 2012; Gharghori et al., 2006, 2009; Tanthanongsakkun and Treepongkaruna, 2008). 


\subsection{Forecast with time-varying variables}

In recent studies of financial distress prediction, the need to take the time dimension into account is increasingly being recognised. LeClere (2000) points out that qualitative response models, such as logistic regression or probit models, employ data from the time period directly preceding the occurrence of the event of bankruptcy. Hence, the model is static in that it disregards the company's entire history preceding the event. Furthermore, the information provided by the estimated model is limiting as the data used to estimate the probability of financial bankruptcy may only be available immediately prior to the event. Shumway (2001) also points out the discordance between single-period bankruptcy prediction models and multiple-period bankruptcy data. He argues that the single-period classification models that have been commonly used for predicting bankruptcy yield biased and inconsistent estimates because they ignore the fact that the characteristics of firms change through time. Liu (2004) also observes that failure rates change with changes in the time series of economic data.

Nam et al. (2008) extends Shumway's (2001) use of multi-period logit to develop a discretetime duration model with time-varying covariates. They examine the effectiveness of timevarying variables, which reflect changes in idiosyncratic firm financial characteristics, in the prediction of corporate bankruptcy in the Korean Stock Exchange (KSE) during the period of the Asian economic crisis in 1998-2000. Their out-of-sample forecasting results show that the multi-period logit model with time-varying covariates provides somewhat better forecasts than a static logit model.

Cole and Wu (2009) also used Shumway's (2001) multi-period logit with time-varying covariates for US bank failure data. They show that the out-of-sample forecast accuracy of their multiperiod hazard model is considerably higher compared to the simple one-period probit model and conclude that the time-varying bank-specific variables enhance forecasting accuracy.

Using time-varying covariates in a Cox model has been rather difficult to implement. Previous studies (for example, Kim et al., 1995; Wheelock and Wilson, 1995) have not reported the baseline hazard estimates since estimates of the baseline hazard are difficult to obtain when covariates in the model are time-varying. The procedure to address this problem is described in the following section.

\section{A dynamic Cox hazards model with time-varying covariates}

The pre-eminent model in survival analysis is the Cox proportional hazards model (Cox, 1972). The key to understanding the Cox model is the concept of the hazard rate, sometimes just called the hazard. The hazard is simply the rate of change of probability over an interval conditional on survival until the start of the interval. The formal definition of the hazard is

$$
h(t)=\lim _{\Delta t \rightarrow 0} \frac{P(t \leq T<t+\Delta t \mid T \geq t)}{\Delta t}
$$

where $T$ is the duration of time up until a firm's failure and is also called time to failure, and $h(t)$ specifies the instantaneous rate of failure at time $T=t$ given the firm survives up to time $t$.

On the basis of the functional form of the hazard rate, it is possible to generate survival functions for each firm. The survival function, $S(t)$, defines the probability that the duration of time till the company experiences the event, $T$, is greater than some time $t$ 


$$
S(t)=P(T>t)=\exp [-H(t)]=\exp \left[-\int_{0}^{t} h(u) d u\right]
$$

where $H(t)$ denotes the integrated or cumulative hazard rate. This allows the survival function to be written in terms of the hazard rate (or hazard function), $h(t)$.

The Cox hazards model is particularly convenient to use in estimating models with timevarying covariates. Here, the predictor variables are allowed to change in value over the observation period. Thus, for example, a vector of ratios providing a firm's return on assets over a 10-year period would be treated as a single variable, but the value of that variable would be updated as the firm is observed over time in the survival model estimations. Cox's hazards model with timevarying covariates can be expressed as (Andersen, 1992)

$$
h_{i}(t \mid z(t))=h_{0}(t) \cdot \exp \left\{\sum_{j=1}^{p} \beta_{j} z_{j}^{i}(t)\right\}
$$

where $h_{i}(t \mid z(t))$ is the time-varying hazard function for firm $i$ at time $t, z_{j}^{i}(t)$ denotes the value of the $j$ th covariate at time $t$ for the $i$ th firm, $\beta_{j}$ is the corresponding coefficient for the vector $z_{j}^{i}$, while $h_{0}(t)$ is the baseline hazard representing the effect of time (the hazard with all covariates set to zero).

Using equation (3), the model is able to 'exploit each firm's time-series data by including annual observations as time-varying covariates' (Shumway, 2001: 102). That is, if a firm has been observed for 12 years in the set of firms potentially at risk of financial distress, the values of each covariate $z_{j}^{i}(t)$ for that firm are allowed to be updated up to 12 times from year to year $(t)$. Consequently, it is possible to retain multiple-year financial information for each firm according to its lifetime (or duration) and make use of all the time-series data within the period to estimate the model's coefficients.

In a dynamic Cox hazards model with time-varying covariates, the value of covariates $z_{j}^{i}(t)$ changes with time. The hazard at time $t$ depends on the value of covariates at time $t\left(z_{j}^{i}(t)\right)$ and therefore the hazard ratio $(H R)$ also varies with time. The definition is as follows

$$
H R(t \mid z(t))=\frac{h_{i}(t \mid z(t))}{h_{0}(t)}=\exp \left\{\sum_{j=1}^{p} \beta_{j} z_{j}^{i}(t)\right\}
$$

Thus, unlike the conventional Cox proportional hazards model where the hazard ratio remains constant, the proportionality assumption in the Cox hazards model with time-varying covariates is no longer maintained. ${ }^{3}$

\section{I. Partial likelihood function}

It is helpful to introduce some concepts in survival analysis in order to understand the estimation of the model. First, the risk set $R(t)$ is defined as the set of firms (individuals) that are observed at risk of event at time $t$. Firms are said to enter the risk set when they become at risk of experiencing the event and leave the risk set either when they are censored or when the event occurs to them (fail or become financially distressed). Being censored means that a firm leaves the risk set for some other reason than experiencing the event, for example the firm may be taken over, or may still survive at the termination of the study. 


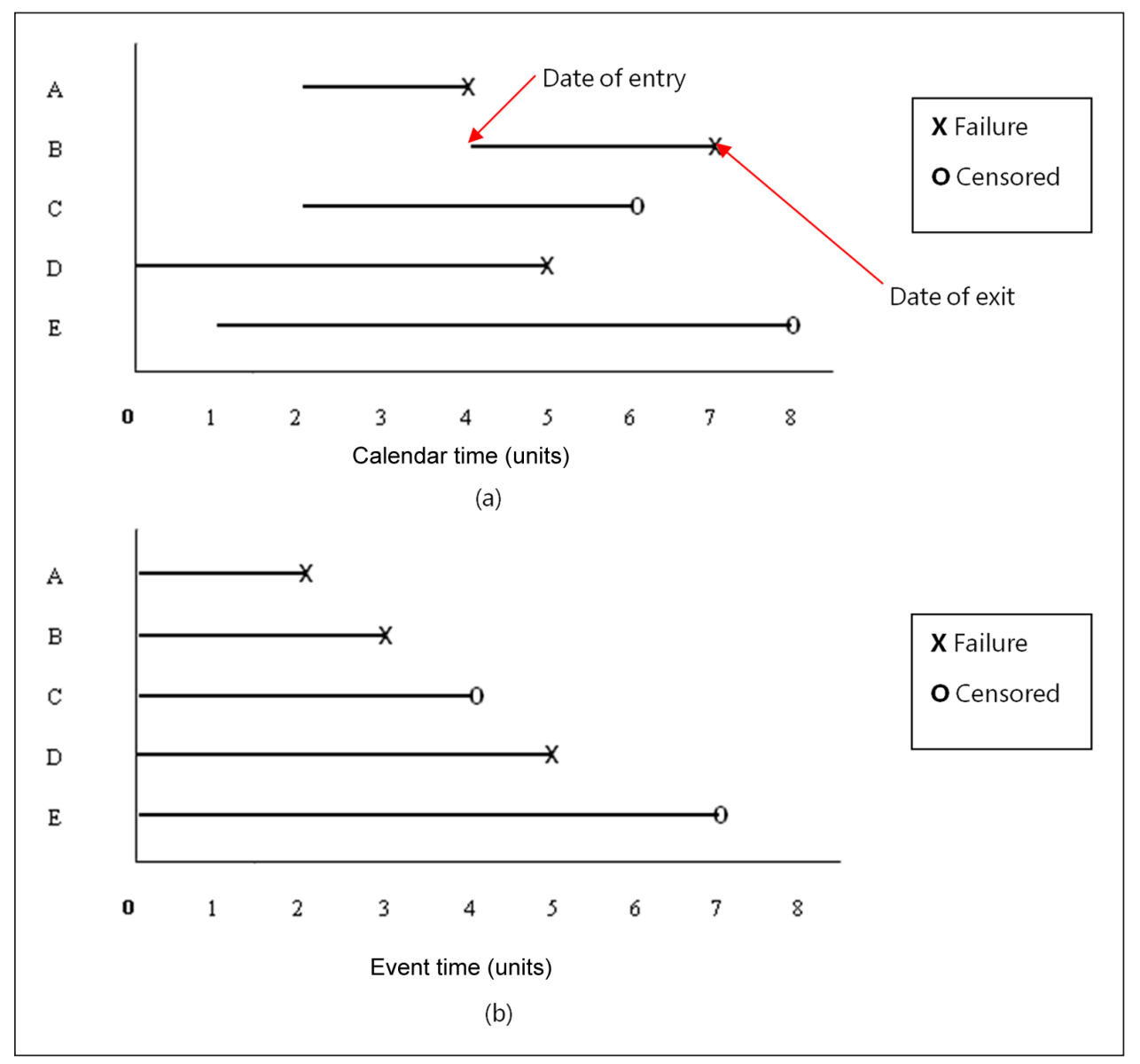

Figure I. Calendar time versus event time.

The figure presents a graphical demonstration of the difference between arranging the data in terms of 'calendar time' and 'event time'. (a) Arrangement of firms in the risk set according to calendar time; (b) Arrangement of firms in the risk set according to event time. It is noted that observations can enter the study at different times in panel (a); however, every observation enters the study at event time 0 in panel (b). The length of the line indicates the lifetime of the observation. An X marker at the end of the line denotes the event of failure, whereas an $\mathrm{O}$ marker indicates that the observation has been censored for reasons other than failure. Each unit indicates a yearly observation.

Second, it is important to distinguish between calendar time and event time. A graphical demonstration of the difference between arranging the data in terms of calendar time and event time is presented in Figure 1.

Figure 1(a) illustrates observations of A to E arranged in calendar time while Figure 1(b) does so in event time. It is noted that observations can enter the study at different times in Figure 1(a); however, every observation enters the study at event time 0 in Figure 1(b). An event time approach looks to the duration (time spent in the risk set) of a firm and sorts observations according to their duration under study. The length of the line indicates the lifetime of the observation. An $\mathrm{X}$ at the end of the line denotes the event of failure, whereas an $\mathrm{O}$ indicates that the observation has been censored for reasons other than failure. The event-time approach is used in our study, as is commonly the case in other survival analysis studies. 
After constructing the risk set at each event time, it is possible to estimate the likelihood of a firm's failure. It is required that the values of time-varying covariates of every firm in the risk set should be measured at each event time. The following equation is written for the ratio of firm $i$ 's hazard to the hazards of all other firms in the risk set for each time $(t)$

$$
L_{i}=\frac{h_{i}(t \mid z(t))}{\sum_{k \in R_{i}(t)} h_{k}(t \mid z(t))}=\frac{h_{0}(t) \cdot \exp \left\{\sum_{j=1}^{p} \beta_{j} z_{j}^{i}(t)\right\}}{\sum_{k \in R_{i}(t)} h_{0}(t) \cdot \exp \left\{\sum_{j=1}^{p} \beta_{j} z_{j}^{k}(t)\right\}}=\frac{\exp \left\{\sum_{j=1}^{p} \beta_{j} z_{j}^{i}(t)\right\}}{\sum_{k \in R_{i}(t)} \exp \left\{\sum_{j=1}^{p} \beta_{j} z_{j}^{k}(t)\right\}}
$$

where $k$ is the firm in the risk set at time $t$ and $p$ is the number of covariates.

Figure 2 illustrates the arrangement of the data in forming the likelihood function of equation (5), where the respective covariate values of yearly observations of a firm's financial performance are updated at every incident of failure. Every time an event of failure is recorded, the vector of coefficients is re-estimated.

Given $L_{i}$ (see equation (5)), the partial likelihood function with the incorporation of timevarying covariates can then be obtained by taking the product of the probabilities across all observed failures, $m$, so that

$$
P L=\prod_{i=1}^{m} L_{i}=\prod_{i=1}^{m}\left[\frac{\exp \left(\sum_{j=1}^{p} \beta_{j} z_{j}^{i}(t)\right)}{\sum_{k \in R_{i}(t)} \exp \left(\sum_{j=1}^{p} \beta_{j} z_{j}^{k}(t)\right)}\right]
$$

where $i$ is the firm in the event of failure and $k$ is the firm in the risk set at time $t$.

\subsection{Difficulties in practical application of a dynamic Cox model to financial distress prediction}

The Cox model using time-varying covariates is more efficient and dynamic in its use of data and is likely to produce less biased and more consistent estimates of financial distress probabilities (Shumway, 2001). However, time-varying models have been difficult to put into practice. The major problems are attributable to breaches of the proportionality assumption and the requirement of having a complete set of covariate measures at every failure time.

In the standard proportional hazards model the hazard for each case is a fixed proportion of the hazard of any other observation at any point in time. Therefore the ratio of hazards for any two observations with independent covariates is constant over time. For two companies, $i$ and $m$, the ratio of the hazards can be expressed such that

$$
\frac{h_{i}(t \mid z)}{h_{m}(t \mid z)}=\frac{h_{0}(t) \cdot \exp \left\{\sum_{j=1}^{p} \beta_{j} z_{j}^{i}\right\}}{h_{0}(t) \cdot \exp \left\{\sum_{j=1}^{p} \beta_{j} z_{j}^{m}\right\}}=\exp \left\{\sum_{m=1}^{p} \beta_{j}\left(z_{j}^{i}-z_{j}^{m}\right)\right\}=k
$$

where $h_{i}(t \mid z)$ is the hazard rate for firm $i$ at time $t, z$ is a row vector of measured covariates $\left(z_{j}^{i}\right.$ denotes the value of the $j$ th covariate for the $i$ th firm) and $\beta$ is a column vector of coefficients ( $\beta_{j}$ 


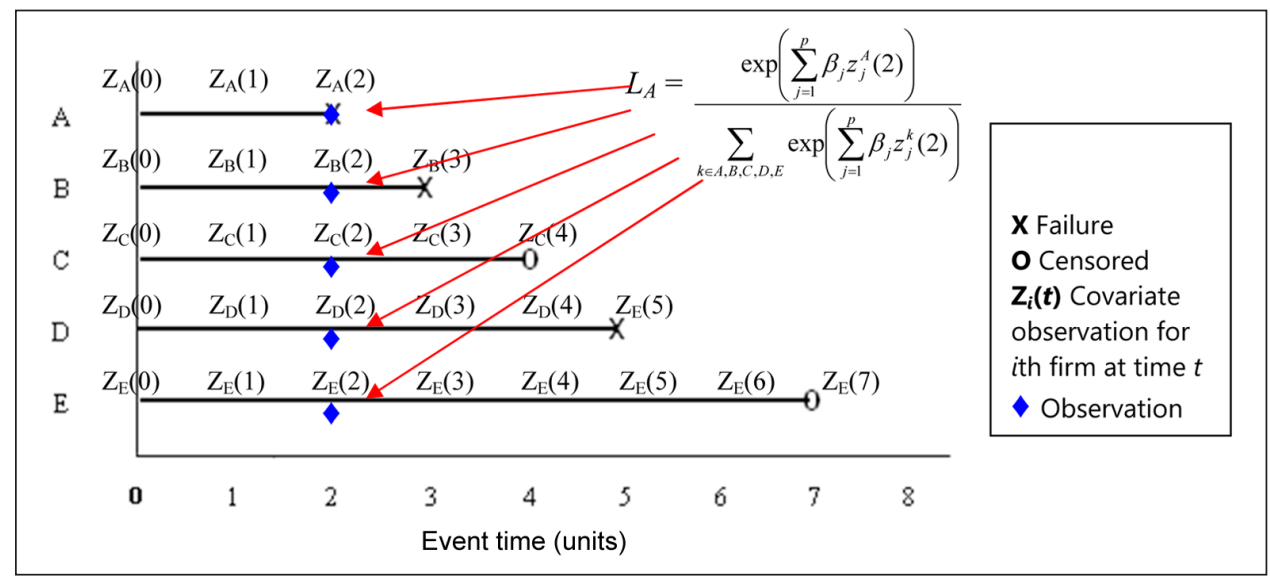

Figure 2. Estimation of the likelihood for the failure of firm A in a dynamic Cox hazards model with timevarying covariates.

The figure illustrates the arrangement of the data in forming the likelihood function in a time-varying model. Observations of $A$ to $E$ are arranged in event time. The model inputs are refreshed at every incident of failure to reflect the observation's covariate values in the risk set at that particular time. Every time an event of failure is recorded, the vector of coefficients is re-estimated. The length of the line indicates the lifetime of the observation. An X marker at the end of the line denotes the event of failure, whereas an $\mathrm{O}$ marker indicates that the observation has been censored for reasons other than failure. Each unit indicates a yearly observation.

is the corresponding coefficient for $\left.z_{j}^{i}\right)$. The components of $h_{i}(t \mid z)$ comprise a baseline hazard, $h_{0}(t)$, which measures the effect of time on the hazard in the absence of covariates, and an exponential term, $\exp \left\{\sum_{j=1}^{p} \beta_{j} z_{j}^{i}\right\}$ that determines the proportional effect of the risk factors. The baseline hazard is assumed to be identical for all entities in the sample. The result is that the plots of the hazard function for all observations are parallel, and consequently this property of proportionality can be exploited in estimating the baseline hazard.

On the other hand, with the time-varying variables the proportionality no longer applies. Since

$$
\frac{h_{i}(t \mid z(t))}{h_{m}(t \mid z(t))}=\frac{h_{0}(t) \cdot \exp \left\{\sum_{j=1}^{p} \beta_{j} z_{j}^{i}(t)\right\}}{h_{0}(t) \cdot \exp \left\{\sum_{j=1}^{p} \beta_{j} z_{j}^{m}(t)\right\}}=\exp \left\{\sum_{j=1}^{p} \beta_{j}\left(z_{j}^{i}(t)-z_{j}^{m}(t)\right)\right\} \neq k
$$

$h_{i}(t \mid z(t))$ is the time-varying hazard function for firm $i$ where the hazard at time $t$ depends on the value of measured covariates at time $t, z_{j}^{i}(t)$ denotes the value of the $j$ th covariate at time $t$ for the $i$ th firm and $\beta_{j}$ is the corresponding coefficient for $z_{j}^{i}$.

The mechanism of time-varying specification requires the covariate values of each observation of a company to be updated at every measurement; therefore, the parameter estimates are recomputed every time a failure event occurs. As a result, the hazard functions for all companies are not parallel anymore, nor are the relative hazards between companies proportional. The outcome is that there is substantial difficulty in estimating the baseline hazard and consequently in forming forecasts. 
Likewise, due to technical difficulties, the current software (for example, SAS (SAS Institute Inc., Cary, NC, USA)) is not capable of generating survival probabilities when the variables are changing with time.

This study implements a procedure, following the approach of Chen et al. (2005), to make it possible to provide survival forecasts with time-varying variables. The parameter estimation process implies that the time-varying covariate values of every firm in the risk set should be recorded and measured at each 'failure time'. In this study there was a missing data problem with respect to stock returns. To resolve this problem, the last observed information is used to impute any missing return values. To address the problem of generating survival probabilities, an integrated baseline hazard is estimated as discussed in the next section.

\subsection{Integrated baseline hazard}

To generate survival probabilities at each time $t$, the baseline hazard function $h_{0}(t)$ needs to be estimated. Chen et al. (2005) estimate the integrated baseline hazard function with time-varying covariates based on Andersen (1992). The integrated baseline hazard function $\hat{H}_{0}(t)$ can be estimated as follows

$$
\hat{H}_{0}(t)=\sum_{\tilde{T}_{i} \leq t} \frac{D_{i}}{\sum_{j \in R\left(\tilde{T}_{i}\right)} \exp \left(\hat{\beta}^{\prime} \cdot z_{j}\left(\tilde{T}_{i}\right)\right)}
$$

where $D_{i}$ is the indicator for whether the firm $i$ experiences the failure, i.e. 0 for survivors and 1 for failures; $\tilde{T}_{i}$ is the failure time for the $i$ th firm; $\hat{\beta}$ is the vector of estimated coefficients; and $z_{j}\left(\tilde{T}_{i}\right)$ is the value of the $j$ th covariate at the failure time of the $i$ th firm.

The integrated baseline hazard function $H_{0}(t)$ can also be written as

$$
H_{0}(t)=\sum_{t_{i} \in t}\left[h_{0}\left(t_{m-1}\right) \times\left(t_{m}-t_{m-1}\right)\right]
$$

where $H_{0}(t)$ is a step function, which is discontinuous at $t_{m}$. This allows the baseline hazard $h_{0}(t)$ to be derived from the integrated hazard.

Using the estimated baseline hazard rate $\hat{h}_{0}(t)$, computed from equations $(9)$ and $(10)$, the estimated hazard rate of firm $i$ with covariates $z_{i}(t)$ at time $t$ is derived as

$$
\hat{h}_{i}(t)=\hat{h}_{0}(t) \times \exp \left(\hat{\beta} \cdot z_{i}(t)\right)
$$

\section{Data and evaluation methods}

\section{I. Sample selection}

The study sample includes publicly listed companies on the Australian Securities Exchange (ASX) from 1995 to 2006. Firms that are in the financial sector, as indicated by their Global Industry Classification Standard (GICS) code, are excluded from the sample. ${ }^{4}$ Annual accounting data are obtained from FinAnalysis ${ }^{5}$ (Aspect Financial) and annual market capitalisation data are provided by Securities Industry Research Centre of Asia-Pacific (SIRCA) and Datastream.

Two data filters are applied to the preliminary dataset. First, a complete set of accounting and market capitalisation must be available for every firm. However, for returns, complete return data was obtained through imputation of missing values as discussed above. The missing data filter was 
applied for two reasons. Firstly, handling missing values causes substantial computational problems and, secondly, including missing value observations is likely to lead to informative censoring. In relation to defaulting firms Sobehart and Stein (2000: 12) state, 'financial and market information are less likely to be complete or reliable in the time period leading up to default'. Therefore missing data may be an indicator of failure. In our study, observations with and without missing values are compared using the Mann-Whitney test. The result shows that the missing data are associated with firms that have more negative profits, higher leverage and more negative cash flow. It appears that observations with missing data are financially weaker than those with complete data and therefore firms with missing observations are more likely to fail. If this is true and these firms were included in the study in instances when data were available and then treated as censored when data were unavailable, this would give rise to informative censoring. In other words, the censoring substitutes for the failure event, and this violates the assumptions underlying the analysis.

The second data filter is that information on the firm's failure event must be available. In order to classify firms into groups of non-failed and failed firms, this study follows the approach of Jones and Hensher (2004) and Chan et al. (2008). Firms are classified as failed if (a) they were delisted due to failure to pay their annual listing fees to the ASX, ${ }^{6,7}$ or (b) there was an appointment of liquidators, insolvency administrators or receivers. ${ }^{8,9}$ Companies' failure events in the sample and the dates of their release to the market in Australia are cross-checked against a number of sources: the ASX's Signal G (Company Announcement data obtained from SIRCA), ${ }^{10}$ the deListed Company Database, ${ }^{11}$ Nothman (1993) and Chan et al. (2008). Resulting from this, 1627 nonfinancial firms are identified with available accounting and market capitalisation data, which comprises 1513 non-failed firms and 114 failed firms in the final sample.

It is noted that company failure happens on specific dates, but there may be varying periods of lag between the failure event and the onset of financial distress. In the absence of the data to model these lags, the advantage of dynamic probability forecasts, giving a trajectory to failure, lies in the potential of providing early warning signs as the trajectory changes.

Additionally, annual accounting and market capitalisation data are collected for each company. Initially, yearly observations of firms' financial performance from 1989 through 2006 were considered. However, the requirement of complete data and availability of the date of failure results in no failure events in study samples between 1989 and 1993 and only one failure event in 1994. ${ }^{12}$ Moreover, the sample sizes are very small for 1989 to 1991. The data on firms failing in this period may have been deleted from our data sources and, if so, this is likely to raise a problem of survivorship bias. Therefore, the observations between 1989 and 1994 are excluded from the study. It is noted that defaults are small in number in some of the subsequent years such as 1995, 1996 and 1998; however, extensive data checking suggests that survivorship bias is not an issue in these later periods.

Table 1 shows the total number of firm-year observations in our study sample, the number of non-failed firm-year observations and the number of failed firm-year observations and the percentages of failed to total firm-year observations for every year over the sample period of 1995 to 2006. In the study sample, there are 9712 firm-year observations in total, where 114 failed observations are found.

The entire sample period (from 1995 to 2006) is divided into two separate samples; an estimation sample (from 1995 to 2002) and a holdout sample (from 2003 to 2006) for tests of predictive accuracy. There are 78 failure events in the estimation period and 36 in the holdout period.

\subsection{Dependent variables}

The only dependent variable for a traditional bankruptcy prediction model such as a MDA or a logit model is the occurrence of an event of interest. Unlike traditional dichotomous dependent 
Table I. Data sample.

\begin{tabular}{lcccl}
\hline Year & $\begin{array}{c}\text { Number of firm- } \\
\text { year observations }\end{array}$ & $\begin{array}{l}\text { Number of non-failed } \\
\text { firm-year observations }\end{array}$ & $\begin{array}{c}\text { Number of failed firm- } \\
\text { year observations }\end{array}$ & $\begin{array}{l}\text { Percentage of failed to total } \\
\text { firm-year observations }\end{array}$ \\
\hline 1995 & 600 & 597 & 3 & $0.5 \%$ \\
1996 & 669 & 665 & 4 & $0.6 \%$ \\
1997 & 673 & 660 & 13 & $1.93 \%$ \\
1998 & 667 & 662 & 8 & $0.75 \%$ \\
1999 & 684 & 676 & 20 & $1.17 \%$ \\
2000 & 742 & 722 & 9 & $2.67 \%$ \\
2001 & 824 & 815 & 16 & $1.09 \%$ \\
2002 & 878 & 862 & 10 & $1.82 \%$ \\
2003 & 905 & 897 & 13 & $0.88 \%$ \\
2004 & 953 & 943 & 5 & $1.05 \%$ \\
2005 & 1,043 & 1,030 & $1.25 \%$ \\
2006 & 1,074 & 1,069 & & $0.47 \%$ \\
\hline
\end{tabular}

This table shows the total number of firm-year observations in our study sample, the number of non-failed firm-year observations, the number of failed firm-year observations and the percentages of failed to total firm-year observations for every year over the sample period of 1995 to 2006. The study sample includes financially distressed (failed) firm data from publicly traded companies on the Australian Securities Exchange (ASX) between 1995 and 2006. In the study sample, there are 9712 firm-year observations in total with II 4 observations of failed firms.

variable models, survival analysis deals with not only the occurrence of the event but also the timing of events, including the duration until the event occurs.

In this study, the event of interest indicates whether the firm evolves to the state of failure, that is, being financially distressed, and the duration represents the period of time between the firm's entry into the risk set and the occurrence of the firm's failure. The event indicator equals 1 if a firm becomes financially distressed, otherwise it equals 0 .

\subsection{Predictor variables}

Key predictors for financial distress with firm-specific variables have been identified from previous bankruptcy studies. Variables are selected from the recent major studies by Sobehart and Stein (2000), Shumway (2001), Chava and Jarrow (2004), Campbell et al. (2008) and Fitzpatrick and Ogden (2011). As this study was conducted based on Australian data, some variables that were found to have been useful in Australian studies are also included (from Castagna and Matolcsy, 1981; Gharghori et al., 2006, 2009; Hensher and Jones, 2007; Jones and Hensher, 2004; Tanthanongsakkun and Treepongkaruna, 2008). A set of fundamental accounting-based and market-based variables chosen from the aforementioned studies is shown in Table 2.

The accounting-based variables include measures of profitability (net income/total assets (NI/ TA)), operating liquidity (working capital/total assets (WC/TA)), book leverage (total liabilities/ total assets (TL/TA)) and cash flow generating ability (net cash flow from operations/total assets $(\mathrm{CF} / \mathrm{TA})$ ). As a group, these ratios capture the strength of the firm's financial position. Operating liquidity (working capital/total assets (WC/TA)) has been chosen as the liquidity measure instead of the current ratio (current assets/current liabilities (CA/CL)). This is because the current ratio in our sample suffers from extreme outliers that might have an undue influence on parameter estimates.

The market-based variables include market-to-book (MB) ratio, relative firm size, market leverage, past returns and volatility. MB is commonly used as a proxy for growth opportunities (Baker 


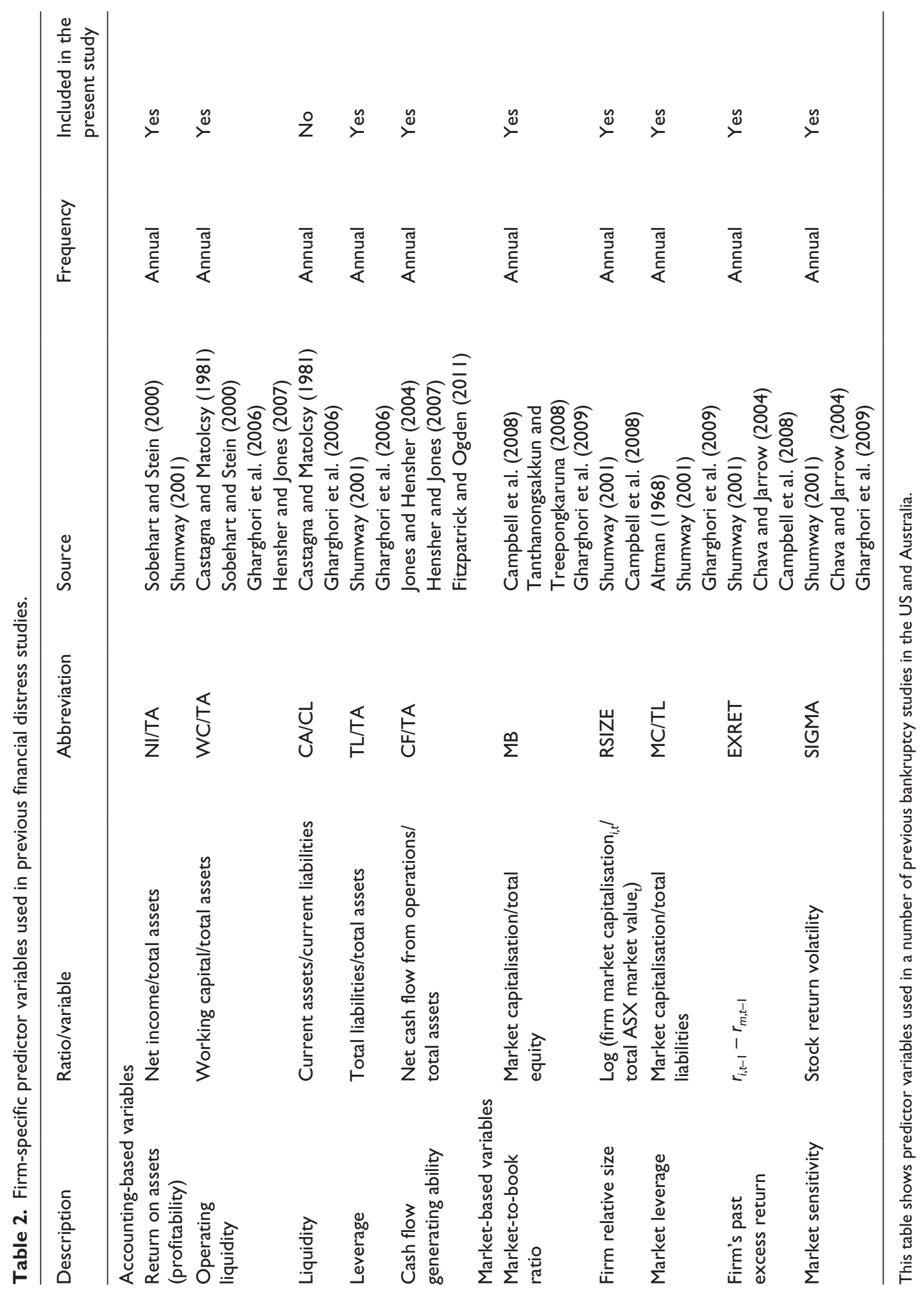


and Wurgler, 2002; Faulkender and Petersen, 2005). Campbell et al. (2008: 2911) demonstrate that MB has a positive effect on the risk of failure 'when market value is unusually high relative to book value'. Other studies invert the ratio and use book-to-market (BM) ratio for growth prospects. Consistent with Campbell et al. (2008), Griffin and Lemmon (2002) and Fitzpatrick and Ogden (2011) find that low BM (high MB) is associated with an increase in default risk. However, the Australian evidence of Gharghori et al. $(2006,2009)$ and Tanthanongsakkun and Treepongkaruna (2008) is that firms with high BM (low MB) have a higher default risk. ${ }^{13}$

The size measure used in this study is the value of the company relative to the value of all companies listed on the ASX. Following Shumway (2001), this variable is measured as $\ln$ (firm market capitalisation $_{i, t} /$ total ASX market value $_{t}$ ), which is denoted as RSIZE. RSIZE is expected to be negatively related to the risk of failure. Market capitalisation/total liabilities (MC/TL) is used as a measure of market leverage. Bigger values of this variable represent lower levels of leverage and it is expected that this variable will have a negative relationship with the risk of failure.

If investors perceive a rising risk of financial distress, they will mark down the value of the firm and this effect will be captured in the excess returns leading up to financial distress. Thus, Shumway (2001) argues that past excess returns should predict financial distress. For Australian listed companies, Frino et al. (2007) document significant negative returns of distressed firms leading up to insolvency announcements, which is consistent with the argument of Shumway (2001). ${ }^{14}$ The firm's past excess return (EXRET) in year $t$ is measured by the excess return of the firm in year $t-1$ over the value-weighted All Ordinary Index return in year $t-1$, where each firm's monthly returns are annualised. The standard deviation of each firm's monthly stock return over the past year is calculated for stock return volatility (SIGMA). The argument of Shumway (2001) is that financially distressed firms would have more volatile cash flows, hence more volatile stock returns.

There are several extreme values among the variables observed. Following the approach of Shumway (2001), all values lower than the first percentile of each variable are set to that value, and analogous treatment is applied to all observations higher than the 99th percentile of each variable. The data, after truncation, are described in detail in Section 4.4.

\subsection{Summary statistics}

Table 3 presents descriptive statistics for annual observations of firm-specific predictor variables used. The minimum and maximum values reported in the table are calculated after truncation. The financial characteristics of non-failed firms are notably in contrast with those of failed firms for most variables. ${ }^{15}$ For example, failed firms are found to have lower levels of profitability, liquidity, cash flow and past excess returns than those of non-failed firms. In contrast, non-failed firms have lower levels of book leverage, market-to-book ratio and volatility. The dispersion of financial ratios among failed firms is also wider than that of non-failed firms, as evidenced by the higher standard deviations.

The first panel in Table 3 (panel A) shows descriptive statistics of firm-specific variables for all firm-year observations of the entire sample. The whole sample includes information for 1627 nonfinancial firms where 9712 firm-year observations are obtained with 114 failure events. Panel B shows summary statistics for all firm-year observations of the estimation sample. There are a total of 1211 firms and 5737 firm-year observations in the estimation sample, of which 78 are failure observations. The holdout sample, as shown in panel C, contains information for 1286 firms with 3975 firm-year observations, where there are 36 failure observations.

Table 3 shows that, on average, profitability (NI/TA) is negative for the whole sample, even for the group of non-failed firms, which implies that the active Australian companies have been experiencing 19\% losses on average from 1995 to 2006. However, this is not a result of poor profits in 
Table 3. Descriptive statistics.

\begin{tabular}{|c|c|c|c|c|c|c|c|}
\hline Variables & Distress group & $N$ & Mean & Median & SD & Minimum & Maximum \\
\hline \multicolumn{8}{|c|}{ Panel A: Descriptive statistics for the entire sample } \\
\hline \multirow[t]{2}{*}{ NI/TA } & Non-failed & 9,598 & -0.1907 & -0.0099 & 0.5537 & -3.6253 & 0.3357 \\
\hline & Failed & 114 & -1.5188 & -0.2360 & 5.0722 & -36.6216 & 0.1437 \\
\hline \multirow[t]{2}{*}{ WC/TA } & Non-failed & 9,598 & 0.0523 & 0.0146 & 0.1855 & -0.5769 & 0.6807 \\
\hline & Failed & 114 & -0.2495 & 0.0028 & 1.1877 & -5.9894 & 0.7888 \\
\hline \multirow[t]{2}{*}{ TL/TA } & Non-failed & 9,598 & 0.3728 & $0.36 \mathrm{II}$ & 0.2941 & 0.0057 & 1.6615 \\
\hline & Failed & 114 & 1.1699 & 0.6144 & 2.1914 & 0.0093 & 14.3223 \\
\hline \multirow[t]{2}{*}{$\mathrm{CF} / \mathrm{TA}$} & Non-failed & 9,598 & -0.0587 & 0.0073 & 0.2903 & -1.6129 & 0.4139 \\
\hline & Failed & 114 & -0.4370 & -0.0597 & I.785। & -10.6183 & 1.5457 \\
\hline \multirow[t]{2}{*}{$M B$} & Non-failed & 9,598 & 2.3805 & 1.4710 & 3.3502 & -4.3710 & 22.6083 \\
\hline & Failed & 114 & 4.0835 & I.0287 & 19.6807 & $-20.688 I$ & 125.4210 \\
\hline \multirow[t]{2}{*}{ RSIZE } & Non-failed & 9,598 & -9.7893 & -10.0927 & 2.0520 & -13.3574 & -4.4020 \\
\hline & Failed & 114 & -10.5446 & -10.6169 & 1.7733 & -13.6954 & -5.4670 \\
\hline \multirow[t]{2}{*}{$\mathrm{MC} / \mathrm{TL}$} & Non-failed & 9,598 & 20.0505 & 3.1941 & 49.3025 & 0.0909 & 340.3319 \\
\hline & Failed & 114 & 22.7777 & 1.2231 & 105.3083 & 0.0061 & 686.0260 \\
\hline \multirow[t]{2}{*}{ EXRET } & Non-failed & 9,598 & 0.1095 & -0.1414 & I. 1357 & -0.9794 & 7.4577 \\
\hline & Failed & 114 & -0.4299 & -0.5352 & 0.4623 & -1.0552 & 1.0579 \\
\hline \multirow[t]{2}{*}{ SIGMA } & Non-failed & 9,598 & 0.1677 & 0.1365 & 0.1216 & 0.0285 & 0.7188 \\
\hline & Failed & 114 & 0.2077 & 0.1822 & 0.1420 & 0.0255 & 0.6747 \\
\hline \multicolumn{8}{|c|}{ Panel B: Descriptive statistics for estimation sample } \\
\hline \multirow[t]{2}{*}{$\mathrm{NI} / \mathrm{TA}$} & Non-failed & 5,659 & -0.1700 & 0.0028 & 0.5304 & -3.6253 & 0.3357 \\
\hline & Failed & 78 & -0.9012 & -0.1624 & 1.9787 & -10.9245 & 0.1437 \\
\hline \multirow[t]{2}{*}{ WC/TA } & Non-failed & 5,659 & 0.0654 & 0.0267 & 0.1859 & -0.5769 & 0.6807 \\
\hline & Failed & 78 & -0.2777 & 0.0132 & 1.2459 & -5.9894 & 0.7888 \\
\hline \multirow[t]{2}{*}{ TL/TA } & Non-failed & 5,659 & 0.3820 & 0.3881 & 0.2854 & 0.0057 & 1.6615 \\
\hline & Failed & 78 & 1.1073 & 0.6174 & 1.9304 & 0.0093 & | 4.3224 \\
\hline \multirow[t]{2}{*}{ CF/TA } & Non-failed & 5,659 & -0.0347 & 0.0212 & 0.2565 & -1.6129 & 0.4139 \\
\hline & Failed & 78 & -0.3031 & -0.0351 & 1.3789 & -10.5883 & I.5457 \\
\hline \multirow[t]{2}{*}{$M B$} & Non-failed & 5,659 & 2.1236 & 1.2944 & 3.0758 & -4.3710 & 22.6083 \\
\hline & Failed & 78 & 4.4430 & 0.8529 & 20.5074 & $-20.688 I$ & 125.4210 \\
\hline \multirow[t]{2}{*}{ RSIZE } & Non-failed & 5,659 & -9.6212 & -9.9260 & 2.0391 & -13.3574 & -4.4020 \\
\hline & Failed & 78 & $-|0.475|$ & $-|0.536|$ & 1.7659 & -13.6954 & -5.467 I \\
\hline \multirow[t]{2}{*}{$\mathrm{MC} / \mathrm{TL}$} & Non-failed & 5,659 & 18.9070 & 2.5557 & 50.0207 & 0.0909 & 340.3319 \\
\hline & Failed & 78 & 13.3508 & 0.8296 & 78.5463 & 0.0061 & 686.0260 \\
\hline \multirow[t]{2}{*}{ EXRET } & Non-failed & 5,659 & 0.0603 & -0.1588 & 1.0470 & -0.9794 & 7.4577 \\
\hline & Failed & 78 & -0.3957 & -0.5047 & 0.4845 & -1.0552 & 1.0579 \\
\hline \multirow[t]{2}{*}{ SIGMA } & Non-failed & 5,659 & 0.1679 & 0.1342 & 0.1250 & 0.0285 & 0.7188 \\
\hline & Failed & 78 & 0.1964 & 0.1822 & 0.1253 & 0.0255 & 0.5772 \\
\hline \multicolumn{8}{|c|}{ Panel C: Descriptive statistics for holdout sample } \\
\hline \multirow[t]{2}{*}{$\mathrm{NI} / \mathrm{TA}$} & Non-failed & 3,939 & -0.2204 & -0.0331 & 0.5843 & -3.6253 & 0.3357 \\
\hline & Failed & 36 & $-2.857 \mid$ & -0.3664 & 8.4710 & -36.6216 & 0.1016 \\
\hline \multirow[t]{2}{*}{ WC/TA } & Non-failed & 3,939 & 0.0334 & 0.0005 & 0.1834 & -0.5769 & 0.6807 \\
\hline & Failed & 36 & -0.1883 & -0.0252 & 1.0647 & -5.9894 & 0.7086 \\
\hline
\end{tabular}


Table 3. (Continued)

\begin{tabular}{llrrrrrr}
\hline Variables & Distress group & $N$ & Mean & Median & SD & Minimum & Maximum \\
\hline Panel C: Descriptive statistics for holdout sample & & & & & \\
TL/TA & Non-failed & 3,939 & 0.3597 & 0.3194 & 0.3056 & 0.0057 & 1.6615 \\
& Failed & 36 & 1.3058 & 0.5928 & 2.6980 & 0.0093 & 14.3224 \\
CF/TA & Non-failed & 3,939 & -0.0931 & -0.0176 & 0.3300 & -1.6129 & 0.4139 \\
& Failed & 36 & -0.7271 & -0.1552 & 2.4451 & -10.6183 & $0.588 I$ \\
MB & Non-failed & 3,939 & 2.7495 & 1.7767 & 3.6782 & -4.3710 & 22.6083 \\
& Failed & 36 & 3.3047 & 1.2259 & 18.0112 & -17.0824 & 104.3650 \\
RSIZE & Non-failed & 3,939 & -10.0306 & -10.3596 & 2.0465 & -13.3574 & -4.4020 \\
& Failed & 36 & -10.6952 & -10.7370 & 1.8051 & -13.6486 & -7.2078 \\
MC/TL & Non-failed & 3,939 & 21.6932 & 4.5846 & 48.2108 & 0.0909 & 340.3319 \\
& Failed & 36 & 43.2025 & 1.7561 & 146.9838 & 0.0239 & 686.0259 \\
EXRET & Non-failed & 3,939 & 0.1801 & -0.1156 & 1.2489 & -0.9794 & 7.4577 \\
& Failed & 36 & -0.5042 & -0.5902 & 0.4066 & -1.0552 & 0.8015 \\
SIGMA & Non-failed & 3,939 & 0.1674 & 0.1398 & 0.1165 & 0.0285 & 0.7188 \\
& Failed & 36 & 0.2319 & 0.1839 & 0.1723 & 0.0429 & 0.6747 \\
\hline
\end{tabular}

Year N Mean Median SD

Panel D: Descriptive statistics of NI/TA grouped by year

$\begin{array}{lrrrr}1995 & 600 & -0.0982 & 0.0260 & 0.4693 \\ 1996 & 669 & -0.0737 & 0.0229 & 0.3569 \\ 1997 & 673 & -0.1038 & 0.0127 & 0.3844 \\ 1998 & 667 & -0.1784 & 0.0077 & 0.5574 \\ 1999 & 684 & -0.1523 & 0.0066 & 0.4778 \\ 2000 & 742 & -0.1336 & -0.0051 & 0.4482 \\ 2001 & 824 & -0.3294 & -0.0372 & 0.8612 \\ 2002 & 878 & -0.2968 & -0.0498 & 0.7146 \\ 2003 & 905 & -0.2806 & -0.0390 & 0.6735 \\ 2004 & 953 & -0.1878 & -0.0206 & 0.6035 \\ 2005 & 1,043 & -0.2141 & -0.0371 & 0.5528 \\ 2006 & 1,074 & -0.2931 & -0.0380 & 1.6779\end{array}$

\begin{tabular}{llll}
\hline Quartile & $N$ & Mean & Median
\end{tabular}

Panel E: Descriptive statistics of NI/TA grouped by firm size (quartile I= small firms)

$\begin{array}{lrrrr}I & 2428 & -0.5247 & -0.1765 & 1.1743 \\ 2 & 2428 & -0.2784 & -0.0794 & 0.9163 \\ 3 & 2428 & -0.0939 & 0.0137 & 0.3983 \\ 4 & 2428 & 0.0341 & 0.0499 & 0.1886\end{array}$

The table shows descriptive statistics for firm-year observations of the ASX listed firms. Each firm has multiple observations according to firm age (duration). NI/TA is the firm's net income divided by its total assets; WC/TA is the firm's working capital divided by its total assets; TL/TA is the ratio of firm's total liabilities to its total assets; CF/TA is the ratio of firm's net operating cash flow to its total assets; MB is the market-to-book ratio of the firm's market capitalisation to its total equity; RSIZE is the firm's relative size measured as the natural logarithm of the ratio of each firm's market capitalisation to that of the ASX All Ordinary Index; MC/TL is the firm's market capitalisation divided by its total liabilities; EXRET is the firm's past excess annual return over the value-weighted All Ordinary Index return; SIGMA is the standard deviation of each firm's monthly returns. Panel A shows descriptive statistics for all firm-year observations for the entire sample over the period of 1995 to 2006. The description of panel B is as for panel A except that it applies to an estimation sample over the period of 1995 to 2002. The description of panel $C$ is also as for panel A except that it applies to a holdout sample for the period of 2003 to 2006. Panels D and E show the statistics of a measure of a firm's profitability, NI/TA, grouped by years and by firm sizes, respectively. SD, standard deviation. 
a specific period. Panel D in Table 3 shows that profitability, on average, has been negative across all years in the sample. This result is attributed to the fact that it is driven by small firms. The valueweighted mean for NI/TA (not reported here) is positive. As shown in panel E of Table 3, if the sample is restricted to the top quartile of firms by size, the mean and median profitability are positive, whereas if the sample is limited to the top half of firms by size, the mean is negative but the median is positive.

The mean excess return for the non-failed firms in the entire sample seems rather high at $10.95 \%$. However, given that the median is $-14.14 \%$, it is clear that the mean is strongly affected by skewness in the distribution. It is noteworthy that the excess returns for the failed firms are strongly negative at $-42.99 \%$ and $-53.52 \%$ for the mean and median, respectively.

Correlation matrices of the nine covariates in the model are constructed for the entire sample, the estimation sample and the holdout sample (see Table 4). The Pearson product-moment correlations are examined. All of the correlations are statistically significant at the $1 \%$ level, but the correlations are not so large as to cause serious concerns about collinearity. The highest correlation at about 0.65 is between net income/total assets and net operating cash flow/total assets.

\subsection{Model evaluation methods}

A model's predictive ability can be assessed in two dimensions: discrimination and precision. Discrimination refers to the model's ability to distinguish between those companies surviving and those failing at a given point in time. Precision refers to the accuracy of the estimated probabilities and is assessed by how well the estimated probabilities reflect the observed outcomes.

4.5. I. Receiver operating characteristics (ROC). To assess the discriminatory power of the models, the survival probabilities are used to classify each firm as failing or surviving, and the resulting classification is compared with the actual outcome. When the probability forecast is converted to a state forecast, picking the optimal cut-off probability for the state transition becomes an issue. Using receiver operating characteristics (ROC) curves is one way to bypass the problem of determining an optimal cut-off point, since it examines the predictive power of the model across the entire spectrum of possible cut-off points (Partington et al., 2001). The ROC curve for a particular model is determined by the hit rate (correctly predicting failures) and the false alarm rate (incorrectly predicting non-failures as failures). The ROC curve plots the combinations of the false alarm rate ( $x$-axis) and the hit rate ( $y$-axis) as the cut-off point is varied across all possible values. A detailed explanation of the ROC curve can be found in Hanley and McNeil (1982), Mason and Graham (1999), Sobehart and Keenan (2001), and Wong et al. (2007).

4.5.2. Scoring rule (Brier score). A proper scoring rule, known as the Brier score, is also used to assess the model's performance (Yates, 1982). While the ROC curves can be used to measure the model's ability to discriminate between those companies surviving and those failing at a given point in time, the Brier score measures the model's precision. The Brier score is calculated as follows

$$
B=\frac{\sum_{n=1}^{N}\left(p_{n}-a_{n}\right)^{2}}{N}
$$

where $N$ is the number of predictions, $p_{n}$ is the predicted probability that a failure event will occur and $a_{n}$ is the actual observation of the event. When a firm fails, then $a_{n}$ equals 1 , otherwise it is 0 . 
Table 4. Correlation matrix of firm-specific variables.

\begin{tabular}{|c|c|c|c|c|c|c|c|c|c|}
\hline Variables & NI/TA & WC/TA & TL/TA & $\mathrm{CF} / \mathrm{TA}$ & MB & RSIZE & $\mathrm{MC} / \mathrm{TL}$ & EXRET & SIGMA \\
\hline \multicolumn{10}{|c|}{ Panel A: Correlation matrix for the entire sample (I995 to 2006) } \\
\hline NI/TA & & 0.3688 & -0.3008 & 0.6389 & -0.0951 & 0.2757 & -0.0785 & 0.0691 & -0.2064 \\
\hline WC/TA & & & -0.3417 & 0.2607 & -0.0654 & 0.1075 & 0.0174 & -0.0142 & $-0.143 \mid$ \\
\hline TL/TA & & & & -0.1005 & -0.0268 & 0.1191 & -0.3125 & -0.0744 & -0.0726 \\
\hline $\mathrm{CF} / \mathrm{TA}$ & & & & & -0.2237 & 0.3531 & -0.1898 & 0.0284 & -0.2541 \\
\hline MB & & & & & & 0.1112 & 0.2642 & 0.1594 & 0.1030 \\
\hline RSIZE & & & & & & & -0.1214 & 0.0798 & -0.4049 \\
\hline $\mathrm{MC} / \mathrm{TL}$ & & & & & & & & 0.1609 & 0.2268 \\
\hline EXRET & & & & & & & & & 0.2800 \\
\hline
\end{tabular}

Panel B: Correlation matrix for estimation sample (1995 to 2002)

\begin{tabular}{|c|c|c|c|c|c|c|c|c|}
\hline NI/TA & 0.3333 & -0.2050 & 0.6494 & -0.0998 & 0.3348 & -0.0825 & 0.0796 & -0.2772 \\
\hline WC/TA & & -0.3156 & 0.1466 & -0.0351 & 0.0838 & 0.0424 & 0.0079 & -0.1365 \\
\hline TL/TA & & & 0.0375 & -0.0158 & 0.1252 & -0.3198 & -0.0695 & -0.0909 \\
\hline CF/TA & & & & -0.2936 & 0.3392 & -0.2370 & 0.0196 & -0.2915 \\
\hline MB & & & & & 0.1226 & 0.2373 & 0.1794 & 0.0955 \\
\hline RSIZE & & & & & & -0.1318 & 0.0954 & -0.4109 \\
\hline $\mathrm{MC} / \mathrm{TL}$ & & & & & & & 0.1828 & 0.2335 \\
\hline EXRET & & & & & & & & 0.2927 \\
\hline SIGMA & & & & & & & & \\
\hline \multicolumn{9}{|c|}{ Panel C: Correlation matrix for holdout sample (2003 to 2006) } \\
\hline NI/TA & 0.4416 & -0.3901 & 0.6401 & -0.0922 & 0.2419 & -0.0788 & 0.0677 & -0.1635 \\
\hline WC/TA & & -0.3927 & 0.4040 & -0.1022 & 0.1323 & -0.0189 & $-0.037 \mid$ & -0.1559 \\
\hline TL/TA & & & -0.2432 & -0.0359 & 0.1060 & -0.3022 & -0.0770 & -0.0474 \\
\hline CF/TA & & & & -0.1449 & 0.3645 & -0.1392 & 0.0452 & -0.2221 \\
\hline MB & & & & & 0.1147 & 0.2989 & 0.1299 & 0.1153 \\
\hline RSIZE & & & & & & -0.1004 & 0.0740 & -0.4015 \\
\hline $\mathrm{MC} / \mathrm{TL}$ & & & & & & & 0.1329 & 0.2171 \\
\hline EXRET & & & & & & & & 0.2694 \\
\hline SIGMA & & & & & & & & \\
\hline
\end{tabular}

This table presents the Pearson product-moment correlations, which are computed from values for each pair of predictor variables. All correlations are significant at the $1 \%$ level (two-sided test). NI/TA is the firm's net income divided by its total assets; WC/TA is the firm's working capital divided by its total assets; TL/TA is the ratio of the firm's total liabilities to its total assets; CF/TA is the ratio of the firm's net operating cash flow to its total assets; MB is the marketto-book ratio measured as the firm's market capitalisation to its total book equity; RSIZE is the firm's relative size measured as the natural logarithm of the ratio of each firm's market capitalisation to that of the ASX All Ordinary Index; $M C / T L$ is the firm's market capitalisation divided by its total liabilities; EXRET is the firm's past excess annual return over the value-weighted All Ordinary Index return; SIGMA is the standard deviation of each firm's monthly returns. Panel A shows the correlation matrices constructed based on the entire sample of $97 / 2$ all firm-year observations over the period of 1995 to 2006 including I I 4 failed firms. Panel B is constructed using the estimation sample, where there are 5737 firm-year observations over the period of 1995 to 2002, including 78 failed firms. Panel $C$ is constructed on a holdout sample, where there are 3975 firm-year observations over the period of 2003 to 2006, including 36 failed firms.

A Brier score of 1 indicates that the model has no predictive power and a score of 0 shows perfect predictive ability. Thus, the lower the Brier score, the better the model's predictive power. 
Table 5. Dynamic hazard model estimates.

\begin{tabular}{|c|c|c|c|c|c|}
\hline Total & Failed & & Censored & & $\begin{array}{l}\text { Percentage } \\
\text { censored (\%) }\end{array}$ \\
\hline \multicolumn{6}{|c|}{ Panel A: Number of failed and censored firms in the estimation sample } \\
\hline 1211 & 78 & & 1133 & & 93.56 \\
\hline Variables & Expected sign & Coefficient & Std error & Chi-square & $p$-value \\
\hline \multicolumn{6}{|c|}{ Panel B: Parameter estimates } \\
\hline $\mathrm{NI} / \mathrm{TA}$ & - & -0.1202 & 0.1063 & 1.2782 & 0.2582 \\
\hline WC/TA & - & -0.3484 & 0.1275 & 7.4678 & 0.0063 \\
\hline TL/TA & + & 0.3532 & 0.0691 & 26.1153 & $<.0001$ \\
\hline CF/TA & - & -0.5083 & 0.2258 & 5.0678 & 0.0244 \\
\hline $\mathrm{MB}$ & $+1-$ & 0.0297 & 0.0072 & 16.8256 & $<.0001$ \\
\hline RSIZE & - & -0.0488 & 0.0717 & 0.4639 & 0.4958 \\
\hline $\mathrm{MC} / \mathrm{TL}$ & - & -0.0070 & 0.0035 & 4.0052 & 0.0454 \\
\hline EXRET & - & -0.9660 & 0.2906 & 11.0515 & 0.0009 \\
\hline SIGMA & + & 0.5550 & 1.0830 & 0.2626 & 0.6083 \\
\hline
\end{tabular}

\begin{tabular}{|c|c|c|}
\hline Criterion & Without covariates & With covariates \\
\hline \multicolumn{3}{|c|}{ Panel C: Model goodness of fit } \\
\hline$-2 \log L$ & 1031.552 & 918.825 \\
\hline Test & Chi-square & $p$-value \\
\hline
\end{tabular}

Panel D: Testing null hypothesis: $\beta=0$
Likelihood Ratio
I 12.7275
9
$<.0001$

Panel A shows the total number of firms, the number of failed firms and the number of censored (non-failed) firms and percentages of censored to the total number of firms in the estimation sample over the period of 1995 to 2002 . Panel B reports the parameter estimates of the Cox hazards model with time-varying covariates. NI/TA is the firm's net income divided by its total assets; WC/TA is the firm's working capital divided by its total assets; TL/TA is the ratio of the firm's total liabilities to its total assets; CF/TA is the ratio of the firm's net operating cash flow to its total assets; MB is the market-to-book ratio measured as the firm's market capitalisation to its total book equity; RSIZE is the firm's relative size measured as the natural logarithm of the ratio of each firm's market capitalisation to that of the ASX All Ordinary Index; MC/TL is the firm's market capitalisation divided by its total liabilities; EXRET is the firm's past excess annual return over the value-weighted All Ordinary Index return; SIGMA is the standard deviation of each firm's monthly returns. A positive coefficient on a particular variable implies that the hazard rate is increasing in that variable. The goodness of fit of each model is presented in panel C. Panel D shows the Likelihood Ratio Chi-Square test against the null hypothesis that at least one of the predictors' regression coefficient is not equal to zero in the model.

\section{Results}

\section{I. Model estimation}

In order to test the predictive power of the dynamic model proposed in this study, the performance of the dynamic model is compared to those of conventional models. The widely used static technique of the logit model and the standard Cox proportional hazards model are chosen as the benchmarks. ${ }^{16}$ All three models for the risk of firm failure are estimated using the estimation sample (from 1995 to 2002) of 1211 firms with 78 failure observations. Table 5 presents the estimated parameters and the goodness of fit measure of the dynamic Cox model. Panel A shows the total 
number of firms used in estimating the model parameters, and the number of failed and censored firms. The resulting coefficient estimates of the model are shown in panel B in Table 5, together with their expected signs and their respective chi-square, and $p$-values (based on a chi-squared statistic for the significance of each coefficient). ${ }^{17}$ The log-likelihood statistics in panel C provide an in-sample goodness of fit measure that shows that the model has significant explanatory power.

Panel B of Table 5 shows that all of the variables have coefficients of the sign expected. Four of the variables are statistically significant at the $1 \%$ level and two at the $5 \%$ level. Of the significant variables, less operating liquidity, lower cash flow generating ability, less market value relative to debt, lower past excess return, a higher level of book leverage and higher market-to-book value increase the probability of failure as expected. A firm's relative size turns out be insignificant in our model whereas it has shown to be the significant predictor in previous studies (for example, Shumway (2001) and Chava and Jarrow (2004)). ${ }^{18}$ Stock return volatility is found to be insignificant. This is consistent with the result of Shumway (2001), where the return volatility lost its significance when it was combined with accounting variables in the model.

The standard Cox proportional hazards model generates similar result to the dynamic model with the notable exception that operating liquidity has a positive sign (opposite to expectation) at the $1 \%$ of significance level. For the logit model, the book leverage and past excess return are statistically significant at the $1 \%$ level. A firm with a higher level of book leverage and less past excess return is likely to have a higher risk of failure. The explanatory power of both models is statistically significant at the $1 \%$ level (unreported ${ }^{19}$ ).

Table 6 shows the dynamic changes of risk scores and corresponding survival probabilities by time horizon using a time-varying Cox hazards model, for 20 randomly selected firms over the period for which each firm was observed. The time-varying risk scores can be calculated for each firm as $\hat{\beta} z_{i}(t)$. Following the approach of Chen et al. (2005), $\hat{\beta}$ is a vector of estimated coefficients as shown in Table 5 and $Z_{i}(t)$ is a vector of values of covariates for firm $i$ at time $t$. For example, the risk score of firm 1 at time 2 is estimated using the estimated coefficients from Table 5 and the values of nine predictor variables for firm 1 at the second year of the firm's lifetime.

The survival probabilities are calculated using the hazard from equation (11) and taking the exponential of the negative integrated hazard (see equation (2)).

Panel A in Table 6 presents the resulting risk scores and survival probabilities for 10 randomly selected firms in the non-failed group, and panel B shows 10 firms in the failed group. Comparing these survival probabilities for the failed firms with those of the surviving firms at the same time horizons (lifetime), the failing firms have lower probabilities. However, in most cases the differences are not great and the survival probabilities for the failed firms are generally high, with several above 0.9.

The explanation for the foregoing seems to lie in the interaction between the risk score and the baseline hazard. Since the incidence of failure in the estimation sample is small, the risk of failure for an average firm is small. Consequently, although the baseline hazard rises through time, it remains small. Thus, to obtain a small probability of survival requires a substantial scaling up of the baseline hazard by the risk score. It appears in this analysis that the risk scores for failed firms are not often large enough to achieve the required scaling up.

\subsection{Model validation}

This section presents the out-of-sample prediction results of the three models estimated. Panel A and panel B in Table 7 present each model's predictive accuracy of the out-of-sample forecast of the time-varying dynamic Cox hazards model, the standard Cox proportional hazards model and the traditional logit model based on ROC curves and the Brier scores. The area under the ROC (AUROC) measures the discriminatory power of the model, and the higher the AUROC the better the model. Predictions made at random have an AUROC of 0.5 and models that do not beat this 


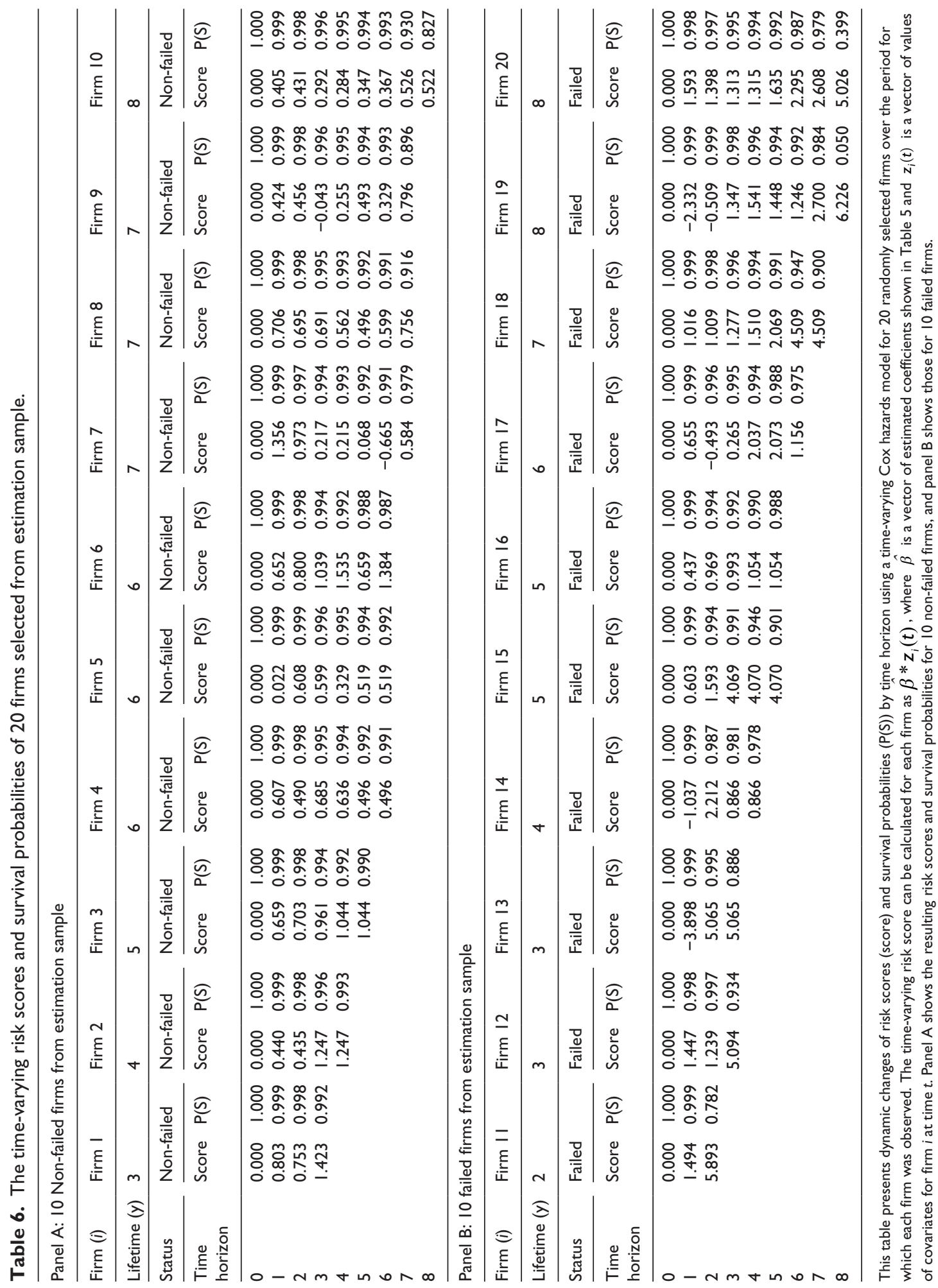


Table 7. Predictive accuracy.

Panel A: Predictive accuracy of the holdout sample - area under the ROC curve

\begin{tabular}{lllll}
\hline Time horizon $(t)$ & Random forecast & Dynamic Cox & Standard Cox & Logit \\
\hline 1 & 0.5 & 0.795 & 0.710 & 0.693 \\
2 & 0.5 & 0.803 & 0.744 & 0.754 \\
3 & 0.5 & 0.724 & 0.696 & 0.573 \\
4 & 0.5 & 0.747 & 0.608 & 0.418 \\
\hline
\end{tabular}

Panel B: Predictive accuracy of the holdout sample - Brier score

\begin{tabular}{lllll}
\hline Time horizon $(t)$ & Naive forecast & Dynamic Cox & Standard Cox & Logit \\
\hline 1 & 0.069 & 0.007 & 0.007 & 0.012 \\
2 & 0.070 & 0.009 & 0.009 & 0.012 \\
3 & 0.064 & 0.012 & 0.015 & 0.026 \\
4 & 0.053 & 0.005 & 0.012 & 0.012 \\
\hline
\end{tabular}

This table shows predictive accuracy of the out-of-sample forecast using the time-varying dynamic Cox hazards model, the time-invariant standard Cox proportional hazards model and the traditional logit model. Panel A examines predictive accuracy using the ROC curves and describes the area under the ROC (AUROC) curves for a holdout sample for the period 2003 to 2006 . The AUROC measures the discriminatory power of the model. The higher the AUROC, the better the model. Predictions made at random have an AUROC of 0.5 and models that do not beat this benchmark have no predictive power. Panel B shows the Brier score, which measures the deviation between the predicted probability of a failure event and the actual outcome of the event at the level of an individual company. The smaller the Brier score, the better the model. The naïve forecast is based on the proportion of defaults to the estimation sample.

benchmark have no predictive power. Panel A examines predictive accuracy using the ROC curves and describes the AUROC for the holdout sample from 2003 to 2006. Panel B shows the Brier score, which measures the deviation between the predicted probability of a failure event and the actual outcome of the event at the level of an individual company. The naïve forecast is based on the proportion of defaults to the estimation sample, which serves as an estimate for the naïve prior probability of failure.

For the dynamic Cox model, the predicted survival probabilities for out-of-sample forecast are computed in the same way as those of in-sample. That is, until the event of failure in the holdout sample, the set of firms' annual observations as at their financial year ends are entered into the model, with the values of covariates being updated as time passes. Thus, the survival probabilities at time $t$ are based on data updated to time $t$. The consequence for failing firms is that the data used are the data last observed prior to failure. For example, a firm survives for two years and fails after the year three data is observed. The first year predicted survival probability based on the covariates observed at the end of year one in the holdout period will be evaluated at time horizon $t=1$, and the second year forecast based on the covariates at the end of year two is assessed at $t=2$. In year three, the third year forecast at $t=3$ is based on the data observed at that time. The firm is then withdrawn from the study because there are no data beyond year three.

It can be problematic to directly compare prediction results of a time-varying dynamic Cox model to those of the standard Cox model and the static logit model. A particular effort has therefore been made so that the data for the static models are aligned with those of the dynamic Cox model. That is, instead of having a set of data collected at a single point in time, all data across time are pooled and arranged according to event time. For example, if a firm has been at the risk set for three years from 2004 to 2006, each yearly observation of this firm would be listed in order and then the first year observation would be tagged as $t=1$, the second year observation as $t=2$, and so on. It is noted that any firm-year observations that belong to a failed (financially distressed) firm 
would be marked as failed observations. By doing this, a firm with three years of observations would end up having three logit-based survival probabilities that change over time.

Overall, the dynamic model has stronger discriminatory power over both the standard Cox model and the logit model across different time horizons (see panel A in Table 7). Interestingly, the model's estimates do not deteriorate at longer horizons. This result is in direct contrast to prior bankruptcy studies, where predictive accuracy tends to decrease sharply as the time horizon lengthens. The results show that by $t=4$ the logit model has a level of discrimination that is even worse than chance (0.5) according to the ROC score. The result from the Brier score (see panel B in Table 7) also verifies that the dynamic models perform better than the other two models across all time horizons.

\section{Conclusions}

Problems with time-varying predictor variables and estimating baseline hazards have been major obstacles in the application of survival analysis to multiple-period bankruptcy data. A significant contribution of the paper is overcoming the problem of making forecasts from a Cox hazards model when the model contains time-varying covariates. In particular the paper enriches the literature on financial distress prediction for Australian firms.

Nine covariates are used, whose values are updated on a yearly basis from 1995 to 2006. The attractive feature of time-varying survival modelling is that it allows for dynamic changes of a firm's risk levels and its corresponding survival probabilities through time.

As the interaction between the financial distress risk and firm-specific accounting-based and market-based ratios is explored, the result obtained suggests that firms with less operating liquidity, less cash flow generating ability, less market value relative to debt, lower past excess return, higher book leverage and higher market-to-book value are more likely to fail, which is partly in line with the results found in Shumway (2001). The combination of a dynamic model and the dynamic updating of input data results in the model maintaining predictive accuracy as the firms are observed to evolve with time. The time-varying Cox hazards model is shown to outperform the standard Cox model and the logit model at each forecast date in the period that the firms are examined.

This paper uses the financial data observed as at the end of the financial year. By doing so, it facilitates the contemporaneous measurement of two different types of data: market data and accounting data. However, daily, monthly or quarterly-based data could be used for some variables.

While the financial distress prediction study in this paper mainly focuses on the use of quantitative (financial) data, the study might be extended to incorporate qualitative information such as auditing quality and industry/business risk analysis, and also consider the role of management and its track record, such as management commitment and management continuity.

\section{Acknowledgements}

The authors acknowledge the Securities Industry Research Centre of Asia-Pacific (SIRCA) for providing the ASX data and the Capital Markets Cooperative Research Centre (CMCRC) for funding support for Maria Kim's PhD scholarship. We thank Professor Tony Chen from National Taiwan University and Dr Li-Sheng Chen from National Yang-Ming University for their SAS Macro programs, test data and advice. Comments received from participants at the 21st Australasian Finance and Banking Conference (AFBC) 2008 are acknowledged. We are grateful to Philip Gharghori and Giang Truong for their helpful comments and constructive feedback. We also like to express our gratitude to Kathy Walsh and an anonymous referee of Australian Journal of Management for their helpful suggestions. This research was initiated when Maria Kim was a PhD student at the University of Sydney.

\section{Funding}

This research received no specific grant from any funding agency in the public, commercial or not-for-profit sectors. 


\section{Notes}

1. A more common approach, as exemplified by Altman (1968), is to estimate five separate models using data one year before the failure, two years before the failure and so on back to year five.

2. Survival analysis is also known as event history analysis, lifetime analysis or duration analysis.

3. When there are no time-varying variables the ratio of hazards for any two firms is constant over time and so traditionally the model has been known as Cox's proportional hazards model.

4. GICS is designed as 'an enhanced industry classification system jointly developed by Standard \& Poor's and Morgan Stanley Capital International (MSCI)' to 'meet the needs of the investment community for a classification system that reflects a company's financial performance and financial analysis' (Standard and Poors, 2002: 4).

5. FinAnalysis is an online database of detailed financial information for all companies listed on Australian Securities Exchange (ASX). As of 1 August 2013, FinAnalysis is now part of Morningstar DatAnalysis Premium (2012).

6. According to the Australian Securities Exchange Listing Rule 16.5, a firm can be removed from the official list if the firm does not pay an annual listing fee (ASX, 2008: ch. 17).

7. McKenzie (2007) argues that financial distress is one of the possible causes to trigger delistings, which, in aggregate, would deter investor enthusiasm for the stock market.

8. According to the Australian Corporations Act (2001), 'three principal forms of bankruptcy proceedings are available under the legislative provisions: (i) voluntary administration (first introduced in Australia in June 1993 under the Corporate Law Reform Act [1992]), (ii) liquidation, and (iii) receivership' (Jones and Hensher, 2004: 1020). Voluntary administration is similar to Chapter 11 provisions in the US, where the company is provided with recovery options for either reorganising and/or reconstructing its business, or making a deed of arrangement with its creditors with a prospect of full recovery in the future (Routledge and Morrison, 2012).

If the deed of arrangement stage is not reached, then the legislation provides for an automatic transition to liquidation. With respect to (ii) liquidation, there are essentially two types of winding-up procedure available: a creditors' voluntary winding up (decided by special resolution of the company) and a court winding up. In the case of (iii) receiverships, the Corporations Act (2001) provides that a secured creditor, in the event of a firm's insolvency, can appoint a receiver (or a receiver and manager) to recover outstanding claims against the company (Jones and Hensher, 2004: 1020).

9. Routledge and Morrison (2012) find that management may strategically choose voluntary administration.

10. The company announcements are available via a 'Signal G' service. They detail announcements lodged with the ASX pursuant to the ASX Listing Rules.

11. deListed is a division of BRG Pacific Pty Limited. deListed provides information on failed companies, including companies suspended from ASX, NZX, NSX and BSX, and includes all historical name changes and delistings for these exchanges, together with administrators/liquidator/receivers declarations for Australian companies (deListed, 2006).

12. It is expected to have a number of failed observations in these time periods as there was an economic crash in Australia in the early 1990s. Nevertheless, the final data sample rarely includes the failure cases in these periods as they do not meet the requirements of complete information of both accounting and market variables.

13. Gharghori et al. $(2006,2009)$ examine cases where the firm's book equity is positive and negative. They find that positive (negative) BM values are positively (negatively) related to the default risk.

14. Shumway's argument on the negative relation between stock returns and the risk of failure is opposite to the risk-based explanations of risk-return relation. Empirical findings in the finance literature have shown mixed results on this relation, which are summarised in Chan et al. (2011).

15. The Wilcoxon (Mann-Whitney $U$ ) test is carried out for each variable to test the significance of differences of firm characteristics between failed and non-failed groups. The test shows the differences are statistically significant at the $1 \%$ level for all variables, except for the WC/TA ratio, for the entire sample and the estimation sample and at the $10 \%$ level for all variables, with the exception of the WC/TA ratio, for the holdout sample. 
16. A detailed specification of the Cox proportional hazards model can be found in Cox (1972) and Allison (1984), and the details of the logit model can be found in Ohlson (1980) and LeClere (2000).

17. The $p$-values are based on a Wald test statistics as given by the squared ratio of the estimated coefficient to its estimated standard error, which is distributed as chi-square.

18. In unreported results where the model was estimated without the past excess return and return volatility variables, relative size was found to be a statistically significant variable with the sign expected.

19. The results of parameter estimates for the standard Cox proportional hazards model and the logit.

\section{References}

Allen DE and Powell R (2012) The fluctuating default risk of Australian banks. Australian Journal of Management 37: 297-325.

Allison PD (1984) Event History Analysis. Beverley Hills, CA: Sage.

Altman EI (1968) Financial ratios, discriminant analysis and the prediction of corporate bankruptcy. Journal of Finance 23: 589-609.

Andersen PK (1992) Repeated assessment of risk factors in survival analysis. Statistical Methods in Medical Research 1: 297-315.

Australian Corporations Act (2001) Commonwealth Consolidated Acts. Available at: http://www.austlii.edu. $\mathrm{au} / \mathrm{au} /$ legis/cth/consol_act/ca2001172/(accessed 1 May 2007).

Baker M and Wurgler J (2002) Market timing and capital structure. Journal of Finance 57: 1-32.

Bandopadhyaya A (1994) An estimation of the hazard rate of firms under Chapter 11 protection. Review of Economics and Statistics 76: 346-350.

Beaver WH (1966) Financial ratios as predictors of failure. Journal of Accounting Research 4: 71-111.

Bonfim D (2009) Credit risk drivers: Evaluating the contribution of firm level information and of macroeconomic dynamics. Journal of Banking \& Finance 33: 281-299.

Campbell J, Hilscher J and Szilagyi J (2008) In search of distress risk. Journal of Finance 63: 2899-2939.

Castagna AD and Matolcsy ZP (1981) The prediction of corporate failure: Testing the Australian experience. Australian Journal of Management 6: 23-50.

Chan H, Faff R and Kofman P (2011) Is default risk priced in Australian equity? Exploring the role of the business cycle. Australian Journal of Management 36: 217-246.

Chan H, Faff R, Gharghori P, et al. (2008) Default risk modeling: A new non-linear approach. Working paper, University of Melbourne and Monash University.

Chava S and Jarrow R (2004) Bankruptcy prediction with industry effects. Review of Finance 8: 609-641.

Chen KC and Lee CJ (1993) Financial ratios and corporate endurance: A case of the oil and gas industry. Contemporary Accounting Research 9: 667-694.

Chen L, Yen M, Wu H, et al. (2005) Predictive survival model with time-dependent prognostic factors: Development of computer-aided SAS Macro program. Journal of Evaluation in Clinical Practice 11: 181-193.

Coats PK and Fant LF (1992) A neural network approach to forecasting financial distress. The Journal of Business Forecasting 3: 9-12.

Cole RA and Wu Q (2009) Predicting bank failures using a simple dynamic hazard model. In: Proceedings of the 22nd Australasian finance and banking conference, Sydney, Australia, 16-18 December 2009.

Cox DR (1972) Regression models and life-tables. Journal of the Royal Statistical Society Series B: Methodological 34: 187-220.

Crapp H and Stevenson M (1987) Development of a method to assess the relevant variables and the probability of financial distress. Australian Journal of Management 12: 221-236.

deListed (2006) Delisted companies. NSW, Australia. Available at: http://www.delisted.com.au/ (accessed 4 April 2007).

Faulkender M and Petersen MA (2005) Does the source of capital affect capital structure? Review of Financial Studies 19: 45-79.

Fitzpatrick J and Ogden J (2011) The detection and dynamics of financial distress. International Review of Finance 11: 87-121. 
Frino A, Jones S and Wong JB (2007) Market behaviour around bankruptcy announcements: Evidence from the Australian Stock Exchange. Accounting and Finance 47: 713-730.

Frydman H, Altman EI and Kao D (1985) Introducing recursive partitioning for financial classification: The case of financial distress. Journal of Finance 40: 269-291.

Gharghori P, Chan H and Faff R (2006) Investigating the performance of alternative default-risk models: Option-based versus accounting-based approaches. Australian Journal of Management 31: 207-234.

Gharghori P, Chan H and Faff R (2009) Default risk and equity returns: Australian evidence. Pacific-Basin Finance Journal 17: 580-593.

Gray S, Mirkovic A and Ragunathan V (2006) The determinants of credit ratings: Australian evidence. Australian Journal of Management 31: 333-354.

Grice JS and Dugan MT (2001) The limitations of bankruptcy prediction models: Some cautions of the researcher. Review of Quantitative Finance and Accounting 17: 151-166.

Griffin J and Lemmon M (2002) Book-to-market equity, distress risk, and stock returns. Journal of Finance 57: 2317-2336.

Hanley A and McNeil B (1982) The meaning and use of the area under a receiver operating characteristics (ROC) curve. Radiology 143: 29-36.

Hensher DA and Jones S (2007) Forecasting corporate bankruptcy: Optimizing the performance of the mixed logit model. ABACUS: A Journal of Accounting Finance and Business Studies 43: 241-264.

Jones S and Hensher DA (2004) Predicting firm financial distress: A mixed logit model. Accounting Review 79: 1011-1038.

Kim Y, Anderson DR, Amburgey TL, et al. (1995) The use of event history analysis to examine insurer insolvencies. Journal of Risk and Insurance 62: 94-110.

Lane WR, Looney SW and Wansley JW (1986) An application of the Cox proportional hazards model to bank failure. Journal of Banking \& Finance 10: 511-531.

LeClere MJ (2000) The occurrence and timing of events: Survival analysis applied to the study of financial distress. Journal of Accounting Literature 19: 158-189.

Liu J (2004) Macroeconomic determinants of corporate failures: Evidence from the UK. Applied Economics 36: 939-945.

McKenzie MD (2007) International evidence on the determinants of the decision to list. Australian Journal of Management 32: 1-28.

Mason SJ and Graham NE (1999) Conditional probabilities, relative operating characteristics, and relative operating levels. Weather and Forecasting 14: 713-725.

Morningstar DatAnalysis Premium (2012) Available at: http://datanalysis.morningstar.com.au/af/dathome? $\mathrm{xtm}$-licensee=datpremium (accessed 3 December 2013).

Nam C, Kim T, Park N, et al. (2008) Bankruptcy prediction using a discrete-time duration model incorporating temporal and macroeconomic dependencies. Journal of Forecasting 27: 493-506.

Nothman P (1993) Record of Liquidations and Receiverships. Sydney: Financial Analysis Publications.

Odom MD and Sharda R (1990) A neural network model for bankruptcy prediction. In: Proceedings of the IEEE international joint conference on neural networks (IJCNN), San Diego, CA, USA, 17-21 June 1990, vol. 2, pp. 163-168.

Ohlson JA (1980) Financial ratios and the probabilistic prediction of bankruptcy. Journal of Accounting Research 18: 109-131.

Partington G, Russel P, Stevenson M, et al. (2001) Predicting return outcomes to shareholders from companies entering Chapter 11 bankruptcy. Managerial Finance 27: 78-96.

Peat M (2007) Factors affecting the probability of bankruptcy: A managerial decision based approach. ABACUS: A Journal of Accounting Finance and Business Studies 43: 303-324.

Routledge J and Morrison D (2012) Insolvency administration as a strategic response to financial distress. Australian Journal of Management 37: 441-459.

Shumway T (2001) Forecasting bankruptcy more accurately: A simple hazard model. Journal of Business 74: $101-124$.

Sobehart JR and Keenan S (2001) Measuring default accurately. Credit Risk Special Report, Risk 14: 31-33. 
Sobehart JR and Stein RM (2000) Moody's public firm risk model: A hybrid approach to modeling short term default risk. Moody's Rating Methodology. Report no. 53853, March. New York: Moody's Investors Service, Inc.

Standard and Poor (2002) Setting the standard - Understanding GICS. Report, Standard and Poor's, a Division of The McGraw-Hill Companies, Inc., New York, USA, July

Tam KY and Kiang MY (1992) Managerial applications of neural networks: The case of bank failure predictions. Management Science 38: 926-947.

Tanthanongsakkun S and Treepongkaruna S (2008) Explaining credit ratings of Australian companies - An application of the Merton model. Australian Journal of Management 33: 261-275.

Wheelock DC and Wilson PW (1995) Explaining bank failures: Deposit insurance, regulation. Review of Economics and Statistics 77: 689-700.

Wilson RL and Sharda R (1994) Bankruptcy prediction using neural networks. Decision Support Systems 11: 545-557.

Wong B, Partington G, Stevenson M, et al. (2007) Surviving Chapter 11 bankruptcies: Duration and payoff? ABACUS: A Journal of Accounting Finance and Business Studies 43: 363-387.

Yates F (1982) External correspondence: Decompositions of the mean probability score. Organizational Behavior and Human Performance 30: 132-156. 